[RADIOCARBON, Vol 28, No. 2A, 1986, P 237-245]

\title{
RADIOCARBON DATING WITH THE UNIVERSITY OF WASHINGTON ACCELERATOR MASS SPECTROMETRY SYSTEM
}

\author{
PIETER M GROOTES, MINZE STUIVER
}

Quaternary Isotope Laboratory and Department of Geological Sciences

\author{
GEORGE W FARWELL, DONALD D LEACH, \\ and FRED H SCHMIDT
}

Nuclear Physics Laboratory and Department of Physics, University of

Washington, Seattle, Washington 98195

ABSTRACT. The University of Washington FN tandem accelerator mass spectrometry (AMS) system has been used in a series of ${ }^{14} \mathrm{C}$ studies. 1) The ${ }^{14} \mathrm{C}$ concentrations in annual growth rings for 1962, 1963, and 1964 of a Sitka spruce, each divided into ten sequential segments, were measured; a full and rapid response of tree-ring cellulose to atmospheric changes in ${ }^{14} \mathrm{CO}_{2}$ is indicated, with a delay, if any, of not more than three weeks. 2) The ${ }^{14} \mathrm{C}$ concentrations in two chemical fractions of dissolved organic carbon and in two fractions (by size) of particulate organic carbon were measured for Amazon River samples from several locations. All contain bomb carbon, but the amounts differ significantly. 3) Algae samples from lakes in the dry valleys of Antarctica were dated in order to assist in the reconstruction of the climatic history of Antarctica. 4) Background studies indicate that the contribution of the AMS system itself to the observed ${ }^{14} \mathrm{C}$ concentrations is equivalent to an age of ca $60,000{ }^{14} \mathrm{C} \mathrm{yr} \mathrm{BP}$; for a prepared sample of $5 \mathrm{mg}$ of carbon the background corresponds to ca 50,000 years.

\section{EXPERIMENTAL TECHNIQUE}

\section{The AMS Apparatus}

The University of Washington AMS system is based upon a Model FN tandem Van de Graaff accelerator; it has been described in detail elsewhere, most recently at the Symposium on Accelerator Mass Spectrometry held in Zürich in April, 1984 (Farwell et al, 1984).

The ${ }^{14} \mathrm{C}$ counts to the detector are normalized either to the ${ }^{12} \mathrm{C}^{-}$or to the ${ }^{13} \mathrm{C}^{+4}$ beam current from standard or unknown source samples. The ${ }^{12} \mathrm{C}^{-}$is measured in a side Faraday cup at the low-energy end of the accelerator simultaneously with the ${ }^{14} \mathrm{C}^{+4}$, whereas the ${ }^{13} \mathrm{C}^{+4}$ beam is measured after full acceleration and after $90^{\circ}$ magnetic analysis. The relevant magnetic fields are altered to achieve the change from mass 14 to mass 13 .

Until recently, the ${ }^{13} \mathrm{C}$ method of normalization gave the more reliable results. However, the tuning parameters of the ${ }^{12} \mathrm{C}$ system have been improved so that our latest results show that the two systems yield the same results within the expected uncertainties. The two systems have been amalgamated into a unified mode of operation, in which both samples (standard and unknown) and isotopes $\left({ }^{13} \mathrm{C}\right.$ and ${ }^{14} \mathrm{C}$ ) are alternated in 30 -second intervals. An industrial controller performs the tasks of shifting the nuclear magnetic resonance frequency to control the magnets, inserting and removing a beam monitor for the accelerated ${ }^{13} \mathrm{C}$, and signaling the computer for on-line data acquisition. The system can be switched from a 1:1 mode, as described, to a 1:5 (or $1: 10$ ) mode in which ${ }^{13} \mathrm{C}$ is measured only in 1 out of 5 (or 10 ) cycles.

We now measure the ${ }^{14} \mathrm{C}$ concentration of modern carbon samples with an accuracy of 1 to $2 \%$, based upon two or more measurements each lasting up to an hour. In such a measurement the actual ${ }^{14} \mathrm{C}$ data collection 
time for the unknown sample is typically ca 600 seconds for ca $10^{4}$ counts. With the exception of the measurements of ${ }^{14} \mathrm{C}$ background, where the ${ }^{14} \mathrm{C}$ count rates are extremely low and the ${ }^{12} \mathrm{C}$ normalization system offers the advantage of greater efficiency, all measurements reported in this paper were made with the ${ }^{13} \mathrm{C}$ system.

Most of our carbon materials are now prepared for AMS by iron-catalyzed hydrogen reduction of $\mathrm{CO}_{2}$ (Vogel et al, 1984), followed by graphitization into a small pellet that can be inserted into the sputter ion source of the tandem accelerator (Farwell et al, 1984).

\section{Reproducibility of Results}

Poisson statistics of a single measurement of an unknown sample against a standard give a standard deviation of $\sqrt{2} \%$ for ca $10^{4}{ }^{14} \mathrm{C}$ counts on each sample; this is generally about equal to or slightly smaller than the standard deviation calculated from the scatter of the results of the individual 30-second cycles during which we take ${ }^{14} \mathrm{C}$ counts on standard and unknown (1.5 to $2 \%)$. Thus, Poisson counting statistics are a major factor in the measurement precision at the 1 to $2 \%$ level.

More important is the reproducibility of results for a given sample. This reflects the effect of differing conditions in the accelerator system on the measurements. Each sample is compared with a standard that precedes it and one that follows it on the sample holder wheel, usually with several other samples being measured during the time interval between. The distribution of the differences between these pairs of measurements of ${ }^{14} \mathrm{C}$ concentration has an average not significantly different from zero and a $1 \sigma$ width of ca $3.2 \%$. (Thirty pairs of measurements were analyzed in obtaining these figures.) Thus, the result of a single measurement is position-independent and has a standard deviation of $2.3 \%$. This is slightly larger than the scatter statistics of 1.5 to $2 \%$ and indicates an additional contribution of ca $1 \%$, most likely from long-term changes in accelerator transmission.

Reproducibility is a crucial test for the performance of an AMS system, since the reproducibility may be poor if the transmission of the system is marginal, even if the scatter statistics and the stability appear satisfactory for each individual measurement.

Our reported standard deviation for the ${ }^{14} \mathrm{C}$ concentration or the age of a sample is based upon the difference between the duplicate measurements or upon the scatter statistics of the individual measurements, whichever gives the larger figure.

\section{RESULTS}

The AMS system described above has been used in several geochemical studies, the results of which are summarized below. More detailed discussions will be published elsewhere.

\section{Rapid Response of Tree-Ring Cellulose to Changing Atmospheric ${ }^{14} \mathrm{CO}_{2}$ Levels}

The annual growth rings for 1962, 1963, and 1964 in a Sitka spruce from the Olympic Peninsula, Washington $\left(47^{\circ} 57^{\prime} \mathrm{N}, 124^{\circ} 33^{\prime} \mathrm{W}\right)$ were selected for detailed sampling to observe how the rapid changes in atmos- 
pheric ${ }^{14} \mathrm{CO}_{2}$ concentration caused by the atmospheric nuclear weapons testing of the early 1960 s were recorded in the cellulose of tree rings. The radial ${ }^{14} \mathrm{C}$ concentration profile obtained can be translated into $\Delta^{14} \mathrm{C}$ (Stuiver \& Polach, 1977) as a function of time using radial growth curves measured on Douglas fir growing under similar conditions in the University of British Columbia Research Forest during these three years (Griffith, 1968). The rapid changes in ${ }^{14} \mathrm{C}$ concentration, especially in the 1963 annual ring, parallel very closely those in the atmospheric ${ }^{14} \mathrm{CO}_{2}$ concentration (Nydal \& Lövseth, 1983; Levin et al, 1985).

Further details of these measurements and their interpretation will be published elsewhere (Farwell $e t a l$, ms).

\section{Amazon River Studies: ${ }^{14} \mathrm{C}$ in Organic Matter}

Understanding the sources of organic materials transported by the Amazon River is essential for constructing the carbon cycle in the Amazon Basin. Riverine inputs of organic matter into the ocean also make a potentially important contribution to the dissolved organic carbon within the ocean (Likens et al, 1981; Hedges et al, in press a) which, next to soil humus, is the largest active organic carbon pool on earth (Mackenzie, 1981).

In a study undertaken with colleagues in the School of Oceanography, we have measured the ${ }^{14} \mathrm{C}$ concentrations in two chemical fractions of dissolved organic carbon and in two fractions by size of particulate organic carbon isolated from water samples of the Amazon River. Significant differences were observed.

Depth- and cross-channel-integrated composite water samples (Richey et al, in press) were taken from the Amazon River at Obidos (near the ocean), from the Rio Negro (a major tributary flowing in from the north, ca $500 \mathrm{~km}$ upstream from Óbidos), and from Itapeúa and Santo Antônio do Içá, farther upstream. The "coarse" (65 to $3000 \mu \mathrm{m})$ and "fine" (0.5 to $65 \mu \mathrm{m})$ suspended particulate organic matter samples isolated at Santo Antônio do Içá comprise a discharge-weighted composite representative of the period 1981-83. The dissolved humic materials were collected on CAMREX Cruise VII (February-March, 1984). They were isolated by adsorption onto macroporous resin (Thurman \& Malcolm, 1981) and then separated into fulvic and humic acid fractions.

Aliquots of all of the dried samples were combusted in a vycor ampule. The purified $\mathrm{CO}_{2}$ was sampled for a separate $\delta^{13} \mathrm{C}$ measurement, and the remainder was reduced by hydrogen over an iron catalyst (Vogel et al, 1984). The resulting samples, each containing 1 to $8 \mathrm{mg}$ of carbon, were prepared for use in AMS as graphitized pellets (Farwell et al, 1984).

The AMS results are listed in Table 1.

The coarse particulate fraction consists mainly of undegraded tree-leaf remains (Hedges et al, in press b). It has a $\Delta^{14} \mathrm{C}$ of $\approx+230 \%$, which is close to that of the present atmospheric $\mathrm{CO}_{2}$ (Levin et al, 1985); this confirms its recent origin as indicated by its physical and chemical composition.

The fine particulate fraction has a $\Delta^{14} \mathrm{C}$ of $\approx+20 \%$ and must, therefore, contain predominantly prebomb carbon. Most probably this is soil organic matter (Hedges et al, in press b). The above gives an upper limit of 
TABLE 1

Amazon River ${ }^{14} \mathrm{C}$ studies

\begin{tabular}{|c|c|c|}
\hline Sample & Location & $\Delta^{14} \mathrm{C}(\% 0)$ \\
\hline \multicolumn{3}{|l|}{ Particulate organic matter } \\
\hline $\begin{array}{l}\text { QLA-31* (coarse) } \\
\text { SPOM } 65 \text { to } 3000 \mu \mathrm{m}\end{array}$ & $\begin{array}{l}\text { Santo Antônio } \\
\text { do Icá }\end{array}$ & $+227 \pm 14$ \\
\hline $\begin{array}{l}\text { QLA-32 (fine) } \\
\text { SPOM } 0.5 \text { to } 65 \mu \mathrm{m}\end{array}$ & $\begin{array}{l}\text { Santo Antônio } \\
\text { do Icá }\end{array}$ & $+19 \pm 19$ \\
\hline \multicolumn{3}{|c|}{ Dissolved organic matter (humic materials) } \\
\hline OLA-33 & Rio Negro & $+344+90$ \\
\hline$\widetilde{Q} \mathrm{LA}-34$ & Obidos & $+290 \pm 14$ \\
\hline $\begin{array}{l}\text { Humic acid fraction } \\
\text { OLA-35 }\end{array}$ & & $+141+18$ \\
\hline QLA-36 & $\begin{array}{l}\text { Rio Negro } \\
\text { Obidos }\end{array}$ & $\begin{array}{l}+141 \pm 18 \\
+180 \pm 12\end{array}$ \\
\hline $\begin{array}{l}\text { Fulvic plus humic (unseparated) } \\
\text { QLA-37 }\end{array}$ & Itapeúa & $+283 \pm 13$ \\
\hline
\end{tabular}

* QLA = code designator for accelerator-dated samples from the Quaternary Isotope Lab (QL) and the Nuclear Physics Laboratory

prebomb carbon of $95 \%$, if pre-bomb and post-bomb carbons are assumed to have $\Delta^{14} \mathrm{C}$ values of $-20 \%$ and $+750 \%$, respectively.

The fulvic acid $\Delta{ }^{14} \mathrm{C}$ values of $\approx+340 \%$ (Rio Negro) and $\approx+290 \%$ (Óbidos) are substantially higher than that of today's atmosphere. This means that a significant fraction of these materials was photosynthesized between 1962 and 1979 .

In contrast, the coexisting humic acids have lower $\Delta^{14} \mathrm{C}$ values: $\approx+140 \%$ (Rio Negro) and $\approx+180 \%$ (Óbidos), and they must, therefore, like the fine particulate matter, contain pre-bomb carbon (at most, $80 \%$ for Rio Negro and $75 \%$ for Óbidos).

In the unseparated fulvic-plus-humic sample taken $400 \mathrm{~km}$ farther upstream at Itapeúa, the $\Delta^{14} \mathrm{C}$ of $\approx+280 \%$ is close to that of the other fulvic acid samples, in agreement with the dominance of fulvic over humic acids observed in the Amazon River system (Ertel et al, in press).

These differing ${ }^{14} \mathrm{C}$ concentrations show, for the first time, that different fractions of the organic carbon in the Amazon River system must have been derived from organic carbon pools with different average residence times. The identification of differences in cycling time provides a better understanding of the carbon cycle in the Amazon River Basin, although the mixing ratios of pre-bomb and post-bomb carbon cannot be determined precisely for the various fractions measured.

\section{${ }^{14} \mathrm{C}$ in Samples from the Dry Valleys, Antarctica}

Remains of blue-green algae that formed mats on the floors of lakes in the Dry Valleys in the Transantarctic Mountains have been used extensively to date moraines and fluctuating lake levels that reflect changing climatic conditions in Antarctica (Stuiver et al, 1981). A set of sediments and moraine materials containing algae was collected by $\mathrm{G}$ H Denton in the Taylor and Garwood Valleys, Antarctica, in 1982-83 and submitted to the Quaternary Isotope Laboratory for dating. After being processed and combusted in the standard way, several samples did not yield enough carbon for 
beta-counting. These were then dated by AMS. The results are summarized in Table 2.

The samples QLA-38, -39, and -40 are all from small cross-valley moraine ridges in lower Taylor Valley. These moraines make up part of the Ross Sea drift and document stages in the retreat from Taylor Valley of a tongue of the grounded ice sheet that filled McMurdo Sound and much of the Ross Sea during the Last Glaciation (Stuiver et al, 1981). The moraines are about halfway between the valley mouth and the maximum position reached by the ice between 17,000 and 21,000 years ago ( $\mathrm{G}$ H Denton, pers commun). The AMS ages of these three samples are in good agreement with ${ }^{14} \mathrm{C}$ ages obtained by beta counting in the Quaternary Isotope Laboratory on samples from other moraines in the same group. These ages fall into two groups, one ca 15,500 or $16,000{ }^{14} \mathrm{C} \mathrm{yr} \mathrm{BP}$ and another close to 13,900 yr (unpub data).

These dates, together with all the dates previously published (Stuiver $e t$ $a l, 1981)$, indicate that this sector of the Antarctic ice sheet fluctuated in phase with northern hemisphere ice sheets during the Last Glaciation.

Samples QLA-41 and -42 from upper Garwood Valley, a small ice-free valley in the McMurdo Sound area, represent lacustrine deposits $6 \mathrm{~m}$ above the present level of the lake that occupies the upper portion of the valley. The results show that lake levels in the McMurdo Sound region were higher ca 2000 to 3000 years ago than they are today, having responded, perhaps, to climatic warming at that time.

A fuller account will be published elsewhere by G H Denton.

\section{${ }^{14} \mathrm{C}$ BACKGROUND MEASUREMENTS}

In Table 3 are presented some data on background ${ }^{14} \mathrm{C}$, selected from a large number of measurements that have been made during recent months.

\section{The AMS System: Natural Graphite}

Samples were machined from a piece of natural graphite from the specimen collection of the Department of Geological Sciences and measured exactly as we measure our graphitized pellets of unknown materials. Since no unwanted ${ }^{14} \mathrm{C}$ is likely to be introduced in the sample preparation

TABLE 2

${ }^{14} \mathrm{C}$ in samples from the Dry Valleys, Antarctica

\begin{tabular}{|c|c|c|c|}
\hline Sample & Location & Material & Age $\left({ }^{14} \mathrm{C}\right.$ yr BP $)$ \\
\hline QLA-38 & Lower Taylor Valley & Algae & $14,590 \pm 220$ \\
\hline СLA-39 & Lower Taylor Valley & Algae & $16,290 \pm 260$ \\
\hline QLA-40 & Lower Taylor Valley & Algae & $16,320 \pm 190$ \\
\hline QLA-41 & $\begin{array}{l}\text { Upper Garwood } \\
\text { Valley }\end{array}$ & Algae & $\begin{array}{r}3560+880 \\
-800\end{array}$ \\
\hline QLA-42 & $\begin{array}{l}\text { Upper Garwood } \\
\text { Valley }\end{array}$ & Algae & $2000 \pm 110$ \\
\hline QI.A-43 & Lovill Bluff, Mt Siple & $\begin{array}{l}\text { Penguin remains } \\
\text { (feather) }\end{array}$ & $2370 \pm 100$ \\
\hline
\end{tabular}


TABLE 3

Sources contributing to a measured AMS ${ }^{14} \mathrm{C}$ sample background

\begin{tabular}{|c|c|c|}
\hline Sample & $\begin{array}{c}\text { Measured }{ }^{14} \mathrm{C} \\
\text { concentration } \\
(\% \text { modern carbon })\end{array}$ & $\begin{array}{l}\text { Apparent age } \\
\left({ }^{14} \mathrm{C} \text { yr BP }\right)\end{array}$ \\
\hline $\begin{array}{l}\text { a) Accelerator/AMS system } \\
\text { Natural graphite }\end{array}$ & 0.045 to 0.12 & 54 to $62 \times 10^{3}$ \\
\hline \multicolumn{3}{|c|}{ b) Reduction and sample preparation/handling plus a) } \\
\hline Low ${ }^{14} \mathrm{C} \mathrm{CO}_{2}$ gas QL-1428 & $0.21 \pm 0.06$ & $49.5_{-2.0}^{+2.7} \times 10^{3}$ \\
\hline $\begin{array}{l}\text { QL-1428* } \\
\text { QL-1428*,** }\end{array}$ & $\begin{array}{r}0.405 \pm 0.05 \\
0.61 \pm 0.07\end{array}$ & $\begin{array}{l}44.3 \pm 0.8 \times 10^{3} \\
40.9 \pm 1.0 \times 10^{3}\end{array}$ \\
\hline $\begin{array}{l}\text { c) Combustion plus a) and } b \text { ) } \\
\text { Anthracite in ampule } \\
\text { Anthracite in routine } \\
{ }^{14} \mathrm{C} \text { combustion system }\end{array}$ & $\begin{array}{c}0.42 \pm 0.03 \\
5.47 \pm 0.55(\text { in } 11.7 \mathrm{mg}) \dagger\end{array}$ & $\begin{array}{l}44.0 \pm 0.6 \pm 10^{3} \\
23.3 \pm 0.8 \times 10^{3}\end{array}$ \\
\hline
\end{tabular}

* After exposure of sample to cesium followed by storage in air, 1/16/85

** After long exposure in ion source to carbon from 1964 wood, 1/17/85

+ In routine ( 1 to $8 \mathrm{~g}$ of $\mathrm{C}$ ) samples the apparent age would be 60,000 to $76,000 \mathrm{yr}$

(a very simple operation for natural graphite), and since the graphite itself is substantially "dead," the measured ${ }^{14} \mathrm{C}$ count rate places an upper limit on the contribution of the AMS system itself to the ${ }^{14} \mathrm{C}$ count rates for unknown and standard samples. We find an "accelerator background" equivalent to ca $0.06 \mathrm{pM}$ (percent modern carbon), or to an age of ca $60,000{ }^{14} \mathrm{C}$ yr BP. (Determinations range from 54,000 to $62,000 \mathrm{yr}$.) This background is all but negligible (perhaps a $2 \% 0$ contribution) in its effect on results such as those presented in the preceding sections.

An apparent ${ }^{14} \mathrm{C}$ background also may be caused by contamination during sample preparation (reduction and graphite pellet production) and/or sample combustion.

\section{Contamination during Sample Preparation}

We made a number of measurements on samples made from QL-1428, a virtually dead $\mathrm{CO}_{2}$ gas (age by beta count: $>56,000 \mathrm{yr}$ ) used in the Quaternary Isotope Laboratory. For AMS this provides a measurement of the sum of the contributions from the reduction process for $\mathrm{CO}_{2}$, the preparation of graphitized pellets from the resulting carbon, and the AMS system, itself. The ${ }^{14} \mathrm{C}$ contents of freshly prepared QL-1428 samples are ca $0.2 \mathrm{pM}$, corresponding to an age of ca $50,000{ }^{14} \mathrm{C}$ yr BP. However, removal of samples from the accelerator, followed by storage in the laboratory and later reinsertion into the accelerator, may be deleterious. The same possibly applies to prolonged exposure to more active samples in the sputter ion source (in our case, carbon from 1964 wood, especially). This can be noted in the ages of 44,000 and 41,000 years for a sample used more than once, and at length (Table 3).

\section{Contamination during Combustion}

$\mathrm{CO}_{2}$ samples were prepared from anthracite, which contains no measurable ${ }^{14} \mathrm{C}$. 
Combustion of ca $10 \mathrm{mg}$ of anthracite was carried out in a small ampule exactly as for the Amazon samples. The AMS ${ }^{14} \mathrm{C}$ result of $0.42 \mathrm{pM}$ represents an equivalent age of 44,000 years. If we correct for accelerator background based on the natural graphite results, this becomes ca 46,000 years. For the Amazon samples $\left(\Delta^{14} \mathrm{C}=+20\right.$ to $\left.+340 \%\right)$ this leads to a correction that is negligibly small. For samples of age 30,000 years or more the correction may be appreciable.

A combustion of ca $15 \mathrm{mg}$ of anthracite, yielding a $\mathrm{CO}_{2}$ sample containing $11.7 \mathrm{mg}$ of carbon, was also carried out in the flow system used for routine ${ }^{14} \mathrm{C}$ combustion, since this was the way the Antarctic samples (8.1 to $76 \mathrm{mg}$ of $\mathrm{C}$ ) had been combusted. The measured ${ }^{14} \mathrm{C}$ concentration was 5.5 $\mathrm{pM}$, equivalent to an age of ca 23,000 years. This reflects the contamination introduced into the Antarctic samples during combustion, most likely due to a memory effect. From the size of the anthracite $\mathrm{CO}_{2}$ sample $(11.7 \mathrm{mg})$ we calculate the amount of modern contaminant $(100 \mathrm{pM})$ added during a normal combustion as $0.6 \mathrm{mg}$ of $\mathrm{C}$. Obviously, this amount is unacceptable for precision AMS measurements, but negligible for normal ${ }^{14} \mathrm{C}$ samples containing 1 to $8 \mathrm{~g}$ of carbon where it would yield apparent ages of 60,000 to 76,000 years for infinitely old samples.

The ages of the Antarctic samples were all corrected for a contamination with $0.6 \mathrm{mg}$ of modern carbon. The corrected ages contain an additional uncertainty because the actual activity introduced by combustion is unknown. The correction, however, is not very sensitive to this and varies, except for the very small sample QLA-38, by $<\sigma$ if activities from 70 to 150 pM are used.

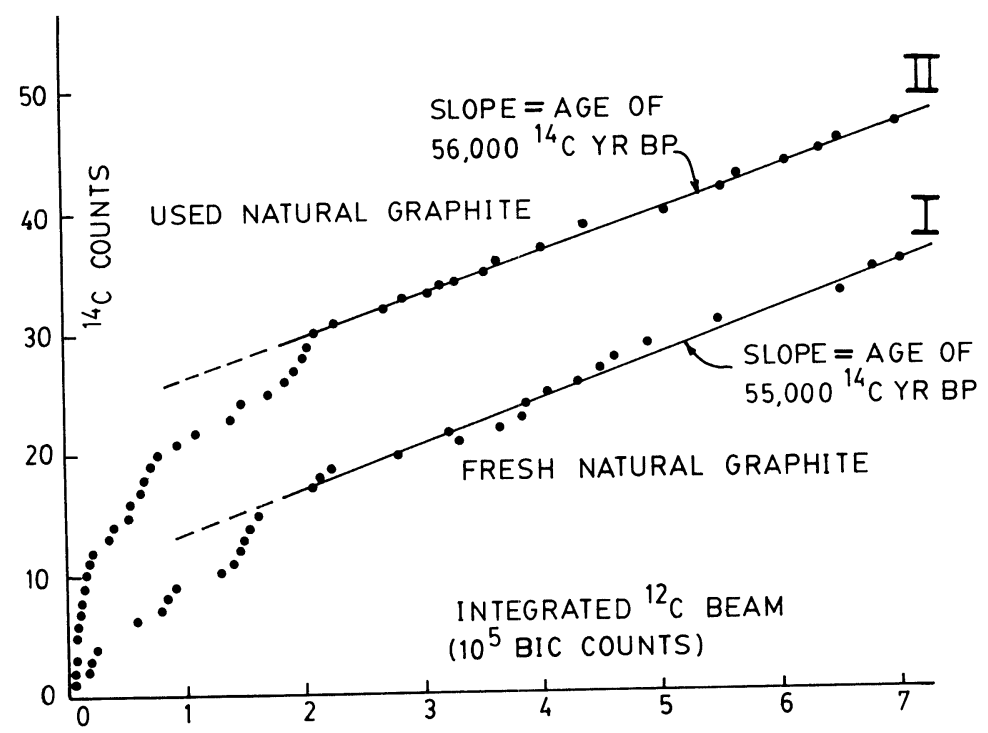

Fig 1 Cumulative ${ }^{14} \mathrm{C}$ counts as a function of integrated ${ }^{12} \mathrm{C}$ beam current for a fresh (I) and a previously used (II) natural graphite sample. A greater initial burnoff of contamination (1/e time: ca $4 \mathrm{~min}$ ) is required for the used sample. The apparent ages are about the same. 


\section{Effect of Atmospheric ${ }^{14} \mathrm{CO}_{2}$ on Prepared Samples}

We have addressed directly the question of possible contamination of samples by atmospheric ${ }^{14} \mathrm{CO}_{2}$ during handling, storage, and reinsertion into the accelerator, and we conclude that such an effect definitely exists. In Figure 1 are plotted the cumulative ${ }^{14} \mathrm{C}$ counts $v$ integrated ${ }^{12} \mathrm{C}^{-}$current $\left({ }^{14} \mathrm{C}\right.$ counts $v s$ time, approximately) for two natural graphite samples, one freshly prepared and one previously exposed (several weeks earlier) in the accelerator. We note in both cases what appears to be a "burnoff period" (steeper slope, more rapid counting rate, at the beginning), followed by a virtually constant slope (constant ${ }^{14} \mathrm{C}$ concentration) after the burnoff. The equilibrium rate corresponds to an age of ca 55,000 years in the first run and 56,000 years in the second (this is satisfactory agreement). The $1 / \mathrm{e}$ time for the burnoff is about four minutes in both cases, but the fresh sample has appreciably less contamination to be burned away. Continued measurement of the fresh graphite sample showed a continuing slow decrease in ${ }^{14} \mathrm{C}$ count rate leading to apparent ages of ca 59,000 and 62,000 years after an additional 1 and 2 hours, respectively.

The problem may be more severe, and the burnoff time greater, with graphitized samples, or with those compounded with a metal (Ag); we have not yet explored this question adequately.

Altogether, we feel that we have quite favorable conditions for the measurement of samples that are very old, and such measurements will occupy a substantial part of our efforts during the months immediately
ahead.

\section{ACKNOWLEDGMENTS}

We are indebted to the following collaborators in the Amazon River study: A H Devol, J R Ertel, J I Hedges, and J E Richey, all of the School of Oceanography, and P D Quay of the Quaternary Research Center and Department of Geological Sciences, University of Washington, and Eneas Salati of the Centro de Energia Nuclear na Agricultura (CENA/USP), Brazil. For a more detailed account, see Hedges $e t$ al, (in press a). The CAMREX (Carbon in the Amazon River Experiment) project is supported by the National Science Foundation (Grant DEB-801-7522) and the Brazilian Conselho Nacional de Desenvolvimento Científico e Technológico. We thank G H Denton for his cooperation in the Antarctic study. David Balsley assisted ably in the experimental work, especially the preparation of carbon samples. The work was supported by the National Science Foundation (Grant EAR-81 15994, Environmental Geosciences Program), the M J Murdock Charitable Trust, and the U S Department of Energy.

$$
\text { REFERENCES }
$$

Ertel, J R, Hedges, J I, Devol, A H, Richey, J E, and Ribeiro, N, in press, Dissolved humic substances of the Amazon River system: Iimnol Oceanog.

Farwell, G W, Grootes, P M, Leach, I I), and Schmidt, F H, 1984, The accelerator mass spec-
trometry facility at ${ }^{14} \mathrm{C}$ etry facility at the University of Washington: current status and an application to the

Farwell, G W, Grootes, P tree cellulose radiocarbon content to Griffith, B G, 1968, Phenology, growth and flower and 
trces on the University Research Forest as influenced by climate and fertilizer, 19571967: Univ British Columbia Forestry Fac, Forestry Bull, v 6, 70 p.

Hedges J I, Ertel, J R, Quay, P D, Grootes, P M, Richey, J E, Devol, A H, Farwell, G W, Schmidt, F H and Salati, E, in press a, Carbon-14 composition of organic matter in the Amazon River system: Science.

Hedges, J I, Clark, W C, Quay, P D, Richey, J E, Devol, A H and dos Santos, U, in press b, Compositions and fluxes of particulate organic material in the Amazon River: Limnol Oceanog.

Levin, I, Kromer, B, Schoch-Fischer, H, Bruns, M, Münnich, M, Berdau, D, Vogel, J C and Münnich, K O, 1985, 25 years of tropospheric ${ }^{14} \mathrm{C}$ observations in Central Europe: Radiocarbon, $\mathrm{v} 27$, no. $1, \mathrm{p} 1-19$.

Likens, G E, Mackenzie, F T, Richey, J E, Sedell, J R and Turekian, K K, 1981, Flux of organic carbon by rivers to the ocean: Washington, DC, U S Dept Energy, NRC-CONF-8009140, $397 \mathrm{p}$.

Mackenzie, F T, 1981, The global carbon cycle: minor sinks for carbon dioxide, in Flux of organic carbon by rivers to the ocean: Washington, DC, U S Dept of Energy, NRCCONF-8009140, p 360-384.

Nydal, R and Lövseth, K, 1983, Tracing bomb ${ }^{14} \mathrm{C}$ in the atmosphere $1962-1980$ : Jour Geophys Research, v 88, p 3621-3642.

Richey, J E, Meade, R H, Devol, A H, Nordin, C F, Salati, E and dos Santos, U, in press, Water discharge and suspended sediment in the Amazon River: a sampling procedure and distributions: Water Resources Research.

Stuiver, M, Denton, G H, Hughes, T J, and Fastook, J L, 1981, History of the marine ice sheet in West Antarctica during the Last Glaciation: a working hypothesis, in Denton, G H and Hughes, T J, eds, The last great ice sheets: New York, John Wiley \& Sons, p 319-436.

Stuiver, $\mathrm{M}$ and Polach H A, 1977, Discussion: Reporting of ${ }^{14} \mathrm{C}$ data: Radiocarbon, v 19, $\mathrm{p}$ $355-363$.

Thurman, E M and Malcolm, R L, 1981, Preparative isolation of aquatic humic substances: Environmental Sci Tech, v 15, p 463-466.

Vogel, J S, Southon, J R, Nelson, D E, and Brown, T A, 1984, Performance of catalytically condensed carbon for use in accelerator mass spectrometry: Nuclear Instruments \& Methods, v 233[B5], no. 2, p 289-293 